\title{
Analyse and Survey Variables of Macroeconomic Effects on Credit Risk of Bank Mellat
}

\author{
MA/MSc Majid Lotfi Ghahroud \\ Ensieh Amini
}

Tehran university, Iran

\begin{abstract}
Trying to identify, measure and manage credit risk in the banking system is crucial. Given that on the one hand financing system of the country is bank-based and on the other hand lack of proper investigation in the credit risk area lead to a reduction in the allocation of resources in the form of loans and has been increased the nonperforming loan. Therefore, concerning about credit risk and its reduction strategies has grown. In this study attempted to examine the impact of macro-economic features, such as GDP, inflation, rate of GDP growth, imports goods and final services, rate of nominal interest, amount of credit risk in the last period and the growth rate of facility to be addressed in Credit risk of the Mellat Bank.Moreover, the effects of macroeconomic conditions on credit risk are investigated. In this regard, credit risk of 52 active branches of Mellat Bank with variables such as GDP growth, GDP rates, inflation,credit growth and nominal interest rate since 1386 to 1391 has been measured by using panel data. To do this, combination of cross-sectional and time-series data (panel data) are used. That means relation between the variables evaluated and tested by using econometric methods such as data compilation methodology (panel data). To estimate the model, to select the best model of conventional panel data, fixed effects and random effects, the $\mathrm{F}$ and Housman tests will be done. In this regard, E-views software utilized and Excel for calculation of variables has been used. Based on the results of research the effect of nominal interest rate, facility growth rate and the grow rate of GDP on the credit risk is significant and positive in contrast, the inflation rate has had a negative effect on credit risk.
\end{abstract}

Keywords: Credit risk, nominal interest, GDP, data compilation methodology (panel data), the facility growth rate

\section{Introduction}

In today's world, the health of financial sector of countries is vital due to the major impact of the financial sector in the blink of economic activity and welfare of the people. Banking is one of the most important economic activity. Banks by organizing and conducting the receipts and expenditures can facilitate trade and lead to market expansion, growth and cultivate of the economy. Also by mobilizing savings and channeling them into productive and commercial enterprises played and going to do a valuable service. (Ebrahimi Shaghaghi and others, 1390:2)

In a market where margins of banks because of increased competition always has been decreased and always will be feeling the pressure to further reduce costs, Credit risk models with predict the loss of failure to repay loans will make an advantage for banks and credit institutions. Credit risk models can conduct granting financial facilities that form an important part of operations of each bank with measuring risk. Since granting loans is always associated with a degree of risk Neglect in this area leads to undesirable results for the Banks. (Piers, 1993)

Given the importance of this issue, this paper shows many determinants of credit risk in credit risk of Mellat Bank. Consider variables that are dependent on varied macroeconomic factors and have never been evaluated for Bank Mellat. Therefore, seems that the results of this paper will clear dark since spots in determining credit risk of Mellat Bank branches. To address this issue, a fundamental question arises as follows:

Is there the significant relationship between credit risk in the Mellat Bank, with macroeconomic factors such as facility growth rate, inflation, imports goods and final services, GDP growth, GDP and nominal interest rate? 
In the following will discuss the answer of referred question. Generally, at the end of the second millennium financial institutions and investors have witnessed many changes in financial markets, with the many crises. Following the mentioned developments, at the beginning of the new millennium the world is in the midst of a technology revolution that some of its dimensions are changing in market operations, increasing access to information, changing in the types of available services to investors, as well as changing in production and distribution services. (Shirinbakhsh et al, 1390)

Meanwhile, same as before the activities of financial institutions are associated with risks and proper management of it causes enhance shareholder returns of related companies. On the other side banking industry also from focus on profitability management that means increase distance of dividends received and interest paid is oriented to modern risk management and efficiency thinking. This plays an important role in the activities of banks and many banks have considered the risks, returns and its management. (JahanKhani and Ghorbani, 1384)

Due to constant changes in environmental factors and economic systems different risks affect the financial structure of the various institutions every day. Different institutions including industrial or manufacturing and service companies or monetary and financial institutions and even the governments with respect to its performance areas face particular risks. The risk has different and misleading meanings. Many people use this word like professional traders, risk managers and all the people. The word of "risk" in its various expressions used to be seen in newspapers and magazines, some of these phrases such as risky assets, business risk, financial risk, systemic risk, portfolio risk, credit risk, non-payment risk, country risk, market risk, operational risk, liquidity risk, transaction risk and so forth can be noted.For probing risks in an organization, all kinds of risks must be examined as a whole. (Pandey, 2009)

Risk has merit mention in any domain which one of these areas is banks and banking activities and banks in economic system are of particular interest due to their importance in this area. Reasons of risk factors in the bank can be explained with its function; because on the one side banks collected people's investments which are responsible for it, on the other side with the use of these funds are carrying out banking operations and economic activity. (Hanafizadeh and Rastkhiz, 1390)

In Iran according to the country's economic structure and for reasons such as underdevelopment of capital markets and other non-banking network and contractual, the responsibility of financing the real economy sectors is with country's banking network. Unfortunately, it has not been very successful in achieving their missions. Now most banks continue their activities and survival of the country are due to governmental supports. Requisite the economic development of a country is having an active and healthy banking system. (Tehrani and Fallah Shams, 1384)

In fact, the banking system is the interface that can link surplus resources with national expenditure optimally. Since the creation of the perfect platform for economic growth and development requires adequate investment in economic sectors and these investments are in need of financing, banks as the main financial system (the base of the banking system), the main role in financing production, trade and consumption sectors and even the government will undertake. (Modares and Zekavat, 1382)

In allocating resources, it is important to note that rate of interest facilities, beyond monetary policy can be used in different economic sectors as a tool for economic policy and the possibility that the risk of non-repayment through interest rate fluctuations to be compensated is largely denied from banks grant facilities. More broadly, the credit risk can be stated as probable losses because of an occurred credit event. Credit event will be real when the contracts' ability to complete its obligations will change. Credit risk is one of the most important risk factor causing in banks and financial companies. (Tehrani and Fallah Shams, 1384)

Lack of attention to the risk issue in banking will bring jeopardizes that can even lead to massive event and loss of a large bank. Because of this stakes and likelihood of big falling in economic activities particularly in the large reputable financial institutions, attention to the risk has been at the helm of affairs of economic institutions. Design and implementation of measuring credit risk model in the banking system will have an effective role in order to enhance country's banking efficiency in resource allocation. In this study, the influencing macroeconomic factors in credit risk will be examined. Predicted variables in this model are Inflation, GDP growth rate and the rate of facilities growth that their significance level relation associated with credit risk will be checked with appropriate statistical tests. The model is designed and tested by using financial and credit data of Mellat Bank. 


\section{Literature review}

History of credit risk assessment returns to innovation and the creation of money era and when money was created to preserve value and used as a means of exchange measure. At that time, people tried to consider their financial ability to give loans to different groups and individuals and lend to people who can repay on due date. However, due to the variables affecting the financial ability of people at that time was very limited. Hence, lenders gave loans to individuals with previous cognition but anyway always borrower's financial ability and power the repay have been considered as one effective factor in lending. Credit risk has not been studied specifically in any internal study (However, the efforts that is taking shape recently). Thus, in these research different related studies in this context as to the same subject will be mentioned.

Kimiagari and colleagues in 1391 have been done a study under the title" Bank credit customers's Credit risk of repayment of the facilities model (Shahreza branch of Bank Melli Iran)". Using the logistic regression a sample of 31 companies that received credit facilities from Shahreza branch of Bank Melli between 1386 and 1390 have been investigated. This work has been done regarding to 28 variables in terms of banking system and experts of this field have been selected and after separation of qualitative and quantitative, 15 main variables were chosen. by creating a table all the information was obtained and then by utilizing SPSS software the results based on relationship of customers with refunds were procured. (Kimiagari et al, 1391)

Ashraf Ahmadian in 1391 has donea study under the title "Credit risk management, challenges in financing Iran's banking system". The aim of research was formulating a model to reduce the existent gaps between the banking system and the private sector in the field of financing,focused to examine the challenges from the perspective of the banking system on the one hand and on the other hand economic enterprises. Finally,a functional approach to reduce the gaps between the banking system and private sector in in the field of financing process improvement is presented. (Ahmadian, 1391)

Ali Samadi and colleagues in 1391 have done a study under the title of "Review the contracts and granting the facilities practices in Islamic banking and their relationship to poverty reduction in society". Authors in this study examine how resource allocation methods, challenges of related issues and allocation of resources in the Iran banking sector in terms of efficiency and granting facilities practices have been assessed.And attempted to assessed contracts and granting facilities practices used by the banking system "j.a.a" from different directions such as fit with the nature of banks as specific economic agents, fit with the structure and objectives of banks, fit with the goals and motivations of customers and their relationship to poverty reduction and etc. Eventually represents a model for the allocation of resources in the bank with twenty-five-year experiences of interest-free Islamic banking in Iran and other banks in the world. (Samadi et al, 1391)

Mahdi Taghavi and colleagues in 1390 have done a study under the title "Review of structural break in the relationship between financial sector development and economic growth and extracting the optimal amount of banking facilities provided to the private sector"

Review of structural break in the relationship between financial sector development and economic growth in different countries with different income levels using the index of providing banking facilities to the private sector proportion to GDP is the main aim of this study through which optimal amount of banking facilities to the private sector be extracted. For this purpose, an experimental endogenous growth model and compilation data includes 45 countries over 48 years has been used. The results of different decades and in different income groups confirm the structural failure in relation to financial sector development and economic growth. The results also show that structural breakpoints and optimal size for financial sector depend on the level of country's development. (Taghavi et al, 1390)

Seyed Morteza Zekavat (1390) in a study under title of "Customer credit risk models of Tose-e Saderat Bank"selected five following financial ratios as variables that explain the significant effects of the separation between the two groups of goodstanding costumers and non-credit worthy by using discriminate analyzing and logistic regression. These variables are current ratio, the ratio of current liabilities to total assets, the ratio of profit before tax deduction to equity, the ratio of profit before tax reduction to net sales. He concluded that between financial variables used in this study "current ratio" has the highest contribution in separating customers into two companies and corporations with high credit risk and low credit risk. Moreover, discriminate analysis and logistic regression methods in terms of credit risk are representing the almost same results in conjunction with classification of Tose-e Saderat Iran Bank's corporative clients. (Zekavat, 1390) 
Reza Heydari and colleagues in 1390 in their study under title of "The effects of macroeconomic indicators on of bad loans" have coped with the impact of macroeconomic shocks on bad loans in the between 1379 and 1387. For this purpose, ARDL model was used. VAR model was used for the dynamic behavior of exogenous variables. According to processed models the impact of variables economic shocks which from the implementation of fiscal and monetary policies such as inflation, growth of non-oil GDP, liquidity and loan interest rates have the highest impact on bad loans of the banking system relative to other macro-economic variables respectively.

Shahchera and Mirhashemi Naini have done a research under title of "Analysis of monetary policy shocks on banking network facilities in Iran between 1380 and 1388" in 1390.In this study, has been tried to explain the theory and design of a model and review of these effects to be addressed with using by GMM estimation method so that the effect of this relationship empirically would be analyzed. In this regard, the results of study indicate that the variables based on capital and liquidity and size, have a significant impact on lending banking network in Iran. On the other hand, these effects can be exacerbated by tightening monetary policy. In fact, traditional conduit bank lending and duct bank capital were confirmed for banking system of Iran although its impact has been limited.

Castro (2013) has done a study with title "Factors macro-economic credit risk in the banking system: about the GIPSI".In this study, the relationship between macro-economic developments and credit risk were studied in countries: Greece, Ireland, Portugal, Spain and Italy have been impressed due to adverse economic and financial conditions recently. The findings of this paper show that all can be executed political criteria to promote growth, employment, productivity and competitiveness and to reduce the public and foreign debt are much essentially to stabilize their economy.

Dasilva and Divino have done a study under title of "The role of banking laws in an economy under credit risk and liquidity shock" in Brazil. The results of this study showed that credit risk is cyclical and default risk depends on structural characteristics. The bank's policymakers can reduce fluctuations in the output by formulating policies to promote efficiency and financial stability.

The Ibrahim and colleagues in 2012 have observed that there is a positive relationship between real output, real bank credit and real stock prices in long term based on their research with tilte interaction between the granting of bank loans, economic conditions, financial shocks and economic insecurity in Malaysia. Nevertheless, with a little adjustment of factual data it can be concluded that rising of granted facilities would boost shares prices and value of both variables; credits and shares are greater than their fundamental values. This is due to the uncertainty of the market. Therefore, growing of insecurity in the market has a negative relationship with output in long terms, which is likely lead to a real reduction in output, real credit and real stock prices. In addition, significant relationship between shocks of interest rate and other variables has been observed.

Talavaran and colleagues (2012) have researched on the relationship between the insecurity of macroeconomic and bank lending in Ukraine. In this study, a dynamic model has been proposed based on maximum profit of banks, which shows banks are reluctant to reduce the proportion of their loans in times of rising uncertainty macroeconomic. It causes the expansion of uncertainty information and in its wake risks of investment also increase.

Paneola et al (2012) have showed that probability of non-default risk in the next year, function of increasing profitability, liquidity, coverage, reduction and activity are subordinate of lever in their study under title of "Credit risk and the impact of the new Basel capital accord in small and medium companies: empirical analysis". Smaller companies and those that with a banking relationship have a higher likelihood of default risk. The findings indicate that a major bank is very keen to getting into the implementation of policies to reduce risk through increasing margin which previously had been very high.

Noora and colleagues (2012) have used the data mining techniques to render a decision tree to assess the credit risk in a research under title of "Credit risk assessment: data mining applications in a rural bank" in Bali. The proposed model has provided a new criterion in analysis of loan applications. Results showed that bank can reduce the inefficient loans to $5 \%$ and banks can also be classified as one of the efficient banks if this model is applied.

Aisen and Franken (2010) have studied on banking credits during financial crisis in 2008 based on comparison between countries. The aim of their study was finding important factors of credit growth after 2008 financial crisis in. In this study, information of 80 countries from January 2002 to May 2009 and the standard sectional econometric techniques have been used. 
One of the main causes of credit contraction after crisis, mounting of credit growth before the crisis has been observed. They also found that by the external shock, countries are affected differently and this difference depends on the developmental level of their major trading partners. Moreover, they showed that accredited reaction are different between banks in different regions of the world due to different characteristics and structural specifications of countries such as international financial integration and financial depth. Eventually, the role of counter-cyclical monetary policy was very important which alleviated the credit crunch after the crisis.

\section{Operational Definition of Variables}

This section devotes to operational definition of each variable in the research hypotheses.

Credit risk: the simplest definition of credit risk is; the probability of happening losses in a transaction. Krohi (2001) defines credit risk in such a way that the risk of non-payment happens when the factors shaping the credit quality of an asset change. According to the Ball Committee (1996), credit risk means when a borrower or his/her partner will not fulfill their obligations.

Nominal interest rate: nominal interest rate is determined in the contract between the lender and the borrower; hence, the debtor is required to pay the specified percentage to the creditor regardless of the levels and trend of the prices; while, in calculating real interest rate, inflation is regarded. The inflation is diminished from official interest rate and what is remained is the real interest which is deposited back to the depositor's account (Tizhoosh, 1992).

Risk: the word risk is taken from Italian word Risicaare meaning insisting on doing bravery work. However, there is not a general consensus on the definition of risk. Risk can be considered as the difference between expected and real values. Some believe that risk is a danger which leads to undesirable adverse outcomes in the future (Hemati and colleagues, 2009).

\section{Objectives and Hypotheses}

The current research aims to identify and evaluate the effect of macroeconomic variables on credit risk of BankMellat.

Thus, due to the significance of the study, the research objectives include:

Evaluating and investigating the most effective macroeconomic indexes on credit risk of BankMellat. This study has been conducted with the aim of identifying the effects of macroeconomic variables on credit risk of BankMellat. Accordingly, the hypotheses are as follows:

There is a meaningful relationship between inflation rate and credit risk in BankMellat.

There is a meaningful relationship between GDP growth rate and credit risk in BankMellat.

There is a meaningful relationship between nominal interest and credit risk in BankMellat.

There is a meaningful relationship between growth rate of bank loansand credit risk in BankMellat.

\section{Population and samples}

All the branches of Bank Mellat have been considered as the population of this study. Thus, screening sampling has been used in this research. Screening sampling is used when the participants are screened due to some limitations. Accordingly, required branches with common featuresfor hypothesis testing are selected within stages; hence, from all the branches of Bank Mellatand due to the limitations of this study, only 52 branches were selected as the population of the present research.

\section{Field of Study}

Subject domain: this study goes around the field of management research focusing on evaluating the effect of macroeconomic variables on credit risk of BankMellat. 
The time of domain: Conducting the study was between 2007 and 2012.

Spatial domain: the branches of BankMellat.

\section{Testing Hypotheses}

This section attempts to evaluate the effect of macroeconomic variables on credit risk of BankMellat based on financial and economic theories as well as available information; therefore, descriptive and correlation methods were used. Data were collected from Stock Organization and calculating variables and econometric analysis were conducted through applying EVIEWS and EXCEL; then the findings were analyzed using financial and economic theories.

Panel data models were used for calculating coefficients and testing hypotheses. In actual fact, lack of considering some of the variables in the structure of the models causes inefficiency in econometrics models; thus, panel data models which are shaped from the combination of time series data and cross-sectional data reveal measureless data better than crosssectional data during a year or time series data at one point. Panel data pertains to past trends of the variables that cause dynamic variables. Therefore, this study relies on experimental method based on econometrics trends using Regression analysis as well as panel data models. As a matter of fact, a great experimental model can signify the relationship between the variables, positive and negative effects, time and place variables, as well as the effect and correlation between the variables well. Accordingly, it can be considered as an appropriate method in testing relationships.

The reason to choose the time interval between 2007 and 2012 is that the researcher had the ability to extract financial statements and notes during the time period of 6 months. For sample selection, the screening method was used in such a way that the required branches with common features and based on research limitations for evaluating and testing hypotheses were selected within stages.

\section{Specification and estimation model}

According to what happened in different sections related to research methods and theories, specified model for investigating the effect of macroeconomic variables on credit risk of BankMellatis as follow:

$$
\begin{aligned}
\mathrm{CR} & =\beta_{o t} \beta_{1} G D P g_{i t}+\beta_{2} G D P_{t t}+\beta_{3} \mathrm{NIR}_{i t}+\beta_{4} I N F_{t t}+\beta_{5} R_{i t}+ \\
& \beta_{6} C R_{(-1) i t}+\beta_{7} I M P_{i t}
\end{aligned}
$$

CRit is credit risk of the bank I in time t. GDPg it is the growth rate of internal gross production of the bank I in time t.NIR it is nominal interest of the bank I in time t.Rit is the growth of facilities of the bank I in time t.INF it is the inflation of the bank I in time t.CR(-1)it is credit risk rate in past duration of the bank I in time t.IMPit is the imports and final services of the bank I in time t. For calculating this equation, panel data models were used for 52 selected branches during 6 years (20072012). For testing homogeneity, the model is estimated as follow using common and fixed coefficient.

Table 1: the results of estimating model based on coefficients with fixed effects

\begin{tabular}{|l|l|l|l|l|}
\hline Regression data & Probability & T data & Coefficient & Variable \\
\hline $\mathrm{F}=363.775$ & 0.417 & 0.500 & 0.290 & $\mathrm{C}$ \\
\cline { 2 - 5 } $\mathrm{R} 2=0.0611$ & 0.224 & 1.217 & 0.057 & GDPg \\
\cline { 2 - 5 } D.W=1.838 & 0.310 & -0.658 & -0.215 & GDP \\
\cline { 2 - 5 } & 0.264 & 1.118 & 0.415 & NIR \\
\cline { 2 - 5 } & 0.172 & -1.367 & -0.044 & INF \\
\cline { 2 - 5 } & 0.393 & 0.533 & 2.80 & CR(-1) \\
\cline { 2 - 5 } & 0.430 & 0.628 & 0.052 & IMP \\
\cline { 2 - 5 } & 0.214 & 1.243 & 0.008 & \multicolumn{2}{l}{} \\
\hline
\end{tabular}

Table 2: the results of estimating model based on coefficients with random effects

\begin{tabular}{|l|l|l|l|l|}
\hline Regression data & Probability & T data & Coefficient & Variable \\
\hline $\mathrm{F}=222.257$ & 0.000 & 5.188 & 1.352 & $\mathrm{C}$ \\
\hline \multicolumn{4}{|c|}{148}
\end{tabular}




\begin{tabular}{|l|l|l|l|l|}
\hline R2=0.208 & 0.081 & -1.748 & -0.360 & GDPg \\
\cline { 2 - 5 } D.W=2.130 & 0.069 & -1.822 & -0.206 & GDP \\
\cline { 2 - 5 } & 0.036 & -2.098 & -0.258 & NIR \\
\cline { 2 - 5 } & 0.001 & -3.160 & -0.0044 & INF \\
\cline { 2 - 5 } & 0.452 & -0.315 & -4.73 & $\mathrm{R}$ \\
\cline { 2 - 5 } & 0.003 & -2.962 & -0.037 & $\mathrm{CR}(-1)$ \\
\hline & 0.002 & -3.029 & -0.005 & $\mathrm{IMP}$ \\
\hline
\end{tabular}

Table 3: The findings of $\mathrm{F}$ and Hasman

\begin{tabular}{|l|l|l|l|l|}
\hline Result & Probability & Degree of freedom & Testing data & Testing type \\
\hline Panel data model & 0.000 & $(51.252)$ & 2.247 & F Limr \\
\hline Random trend & 0.128 & 7 & 11.248 & hasman \\
\hline
\end{tabular}

Econometric tests including $\mathrm{F}$ and Hasman reveal that random method estimation is better; however, the results show that none of the coefficients are meaningful. Therefore, estimation has been also done through fixed effect method and common squares. The results are more compatible with common squares; thus, the analysis was based on common squares. Accordingly, the research model is presented as follow:

Table 4: The findings of the estimation based on common square method

\begin{tabular}{|l|l|l|l|l|}
\hline Regression data & Probability & T data & Coefficient & Variable \\
\hline F $=265.928$ & 0.0472 & 0.719 & 0.093 & C \\
\cline { 2 - 5 } R2=0.053 & 0.000 & 5.723 & 0.060 & GDPg \\
\cline { 2 - 5 } & 0.326 & -0.983 & -0.056 & GDP \\
\cline { 2 - 5 } & 0.005 & 2.794 & 0.239 & NIR \\
\cline { 2 - 5 } & 0.000 & -4.455 & -0.030 & INF \\
\cline { 2 - 5 } & 0.157 & 1.416 & 1.92 & CR(-1) \\
\cline { 2 - 5 } & 0.002 & 3.093 & 0.045 & IMP \\
\cline { 2 - 5 } & 0.000 & -6.488 & 0.009 & \\
\hline
\end{tabular}

After that, $\mathrm{F}$ for homogeneity test was calculated as follow:

$$
\begin{aligned}
& H_{0}: \alpha_{1}=\alpha_{2}=\cdots=\alpha_{n}=\alpha \\
& H_{1}: \alpha_{1} \neq \alpha_{2} \neq \cdots \neq \alpha_{n} \neq \alpha \\
& F_{N-1, N T-N-K}=\frac{\left(R_{u r}^{2}-R_{r}^{2}\right) /(N-1)}{\left(1-R_{u r}^{2}\right) /(N T-N-K)} \\
& \mathrm{F}=((0.6593-0.5812) /(51)) /((1-0.9474) /(253)) \\
& \mathrm{F}=1.15
\end{aligned}
$$

By comparing calculated $F$ with $F$ table with the same degree of freedom in numerator and denominator (15/2), it is observed that the first hypothesis related to the width from common origin for all sections is rejected in contrast with the second hypothesis pertinent to the width from different origin. Therefore the top model is the model with width from similar origin for different interceptions which is presented in the following: 


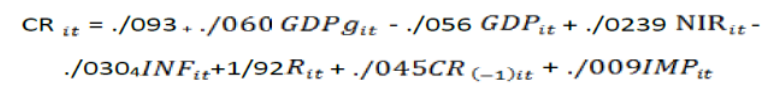

CRit $=0.093+0.060-0.056+0.0239-0.030+1.92+0.045+0.009$

$\mathrm{SE}=(0.129)(0.010)(0.057)(0.085)(0.006)(1.35)(0.014)(0.001)$

t-s=(0.719)(5.723)(-0.983)(2.794)(-4.455)(1.416)(3.093)(6.488)

$\mathrm{R} 2=0.58 \quad \mathrm{~F}=60.09 \quad \mathrm{DW}=1.832$

Through reviewing the results, it is identified that: this hypothesis relying ona negative relationship between GDP rate and inflation rate as well as a positive relationship between GDP growth rate, imports, final services, nominal interest rate, credit risk rate and the growth rate of bank loans in the last period is verified. Accordingly, with one percent increase in credit risk, the percentage of GDP rate, imports, final services, nominal interest rate, credit risk rate in last period and the growth rate of bank loans and their credit risk will increase 0/60, 0/239, 1/92, 0/045, and 0/009 respectively. With one percent increase in credit risk, GDP growth and inflation rate will decrease $-0 / 056$ and $-0 / 030$ respectively. Accordingly, GDP rate, imports, final services, nominal interest rate, credit risk rate in last period and the growth rateof bank loans have the greatest impact and inflation has the least impact on their credit risk. In other words, the best instrument for determining credit risk of the surveyed banks is to increase GDP rate and their nominal interest rate.

\section{The analysis of research findings}

In the last decades, different theories related to the changes in bank credit risk were presented by financial experts. The major emphasis of these theories is whether macroeconomic factors influence on bank credit risk with the change in funds. Different experimental studies have been conducted which resulted in verification or rejection of mentioned theories. However, in different theories, various factors influencing on bank credit risk has beenraised and the effect of these factors on different branches and societies have been investigated. Based on theoretical foundation and previous studies, we are going to analyze our research findings.

The first hypothesis: the obtained results from testing the relationship between inflation and credit risk of confidence level $0 / 99$ reveal that there is a meaningful and negative relationship between variables. There is a negative relationship between inflation rate in the last period and credit risk. The reason is that inflation rate which leads to increasing the value of assets causes the borrowers prefer to settle their debts to release their mortgage.

The second hypothesis: in the first hypothesis the relationship between GDP growth rate and credit risk between 1386 and 1391 was evaluated. The results reveal that there is a positive relationship between GDP rate and credit risk which is meaningful in the confidence level of 0/99. Regarding estimated parameters, the sign of GDP rate is positive which is corresponded with theoretic foundation. In other words, the increase of GDP rate will result in receiving bank loans; thus, the banks compete with each other to loan regardless of the borrowers'credit quality as well as their standards. On the other hand, the optimistic borrowers towards the economy in the future will request loans from the banks.

The third hypothesis: the third hypothesis is pertinent to the relationship between nominal interest rate and credit risk in Bank Mellat. The result of testing hypothesis reveals that there is a positive relationship between nominal interest rate and credit risk with the confidence level of 0/99. Most of the late studies have attempted to identify the macroeconomic variables which can predict banking crises well. The most emphasized variables include: low output growth, high interest rate, and the growth of bank loans.

The forth hypothesis: the last hypothesis concerns with the relationship between the growth rate of bank loans and credit risk in Bank Mellat. Testing hypothesis shows that there is a positive relationship between the growth rate of bank loans and credit risk with the confidence level of 0/99. Accordingly, the growth rate of bank loans is positive. Increasing bank loans as well as lack of considering borrowers' credit quality and standards cause bank credit risk. Therefore, the findings of the study reveal that there is a positive relationship between the growth rates of bank loans. One percent increase in credit risk and the growth rate of bank loans causes the credit risk goes up 0/09.

\section{Conclusion}


As we know the banks can open markets and cause economic growth with controlling the payments; therefore, they can develop economy through savings and moving them towards manufacturing firms. Looking at the financial status in Iran which is bank-based, credit risk is required to be reviewed and evaluated. In the current study, four major macroeconomics and their influence on credit risk of BankMellat were evaluated. The following results have been summarized including:

Inflation coefficient in 52 branches of Bank Mellat on credit risk is negative and meaningful.

The coefficient of GDP growth rate in 52 branches of Bank Mellat on credit risk is positive and meaningful.

The coefficient of nominal interest rate in 52 branches of Bank Mellat on credit risk is positive and meaningful.

The coefficient of bank loans in 52 branches of Bank Mellat on credit risk is positive and meaningful.

Regarding the difference between the coefficients of the variables in panel data model in all the branches of Bank Mellat, it can be concluded that nominal interest rate has been considered as the most influential factor on bank credit risk.

Based on the findings of the study, borrowers prefer to settle their debts when inflation rate causes their assets valuable; thus, it leads to decreasing credit risk. Increasing GDP rate also includes two consequences; in one hand, the growth rate of bank loans increases and on the other hand, credit risk goes up due to being optimistic towards the economy in the future. Accordingly, interest growth rate as well as bank loans normally causes credit risk. As a result, the growth of bank loans leads to the growth of failure to collection. Therefore, banking system is required to consider some macroeconomic variables, namely, inflation and GDP rates to apply the appropriate policy in credit risk field.

\section{Research suggestions}

Based on the findings of the present study, some suggestions will be provided for the improvement of the bank credit system.

Systematizing credit risk data is needed to be regarded. Different models of credit risk have not been systematically applied in the banks for ranking customers.

Macroeconomic status, predicting future, and evaluating the borrowers should be emphasized more.

Lack of independent credit risk, measuring, and controlling credit risk are considered as the weaknesses of the banking system. Although credit risk is active in different banks but it does not function well.

The amount of previous loans which have not been paid yet show that borrowers have not been evaluated well. Therefore, evaluating the borrowers should be focused completely.

Banks are required to consider standards as well as Ball committee guides to determine capital adequacy and accepted risk. Some other banking system requirements are to consider the guidance of Central Bank of the Islamic Republic of Iran related to credit risk in the banks, to determine integral and efficient approach, and to control credit risk functions.

\section{References}

[1] Armashi, Mina (2011). Identifying effective variables on credit risk of real customers of Bank Saman (North of Iran branches), published thesis, Human Sciences University.

[2] Asli, Sholeh (2011).Credit risk management through reviewing loans in other countries, Bureau of Investigation and Risk Control of Bank Sepah.

[3] Arshadi, Ali, zamanzadeh, Hamid (2011). Evaluating achievements and challenges monitoring in Iranian bank system. Journal of New Economics, 9, 134.

[4] Ebrahimi Shaghaghi, Marzieh, Safari, Saeeid, and Taherifard, Morteza (2011). Planning ranking model of real customers in commercial banks focusing on scientific data analysis, comparative study of financial and non-financial indexes. Economic Sciences, 6(12), p. 13.

[5] Hanafizadeh, Payam, RastekhizPaydar, Neda (2011). Journal of Insurance, 102, pp. 55-82. 
[6] Rostami, Ali, RanjbarFallah, Mohammadreza, KhademAlhasaniArdakaei, Majid and JamaliNeishaboori, Ali, Alimohammadi, Maysam (2013). Credit papers: legal, practical, and economic feasibility to associate economic level to improve credit risk. Investment Knowledge, 3(9), pp. 187-205.

[7] SohrabiJahromi, Ali (2011). Investigating the effect of audit procedures in financial statements. Audit Knowledge, 11(45), pp.104-126.

[8] Sekaran, Oma (2011). Research methods in management. Mohammad Saebi and Mahmood Shirazi, Tehran, 8.

[9] Shirinbakhsh, shamsollah, Yousefi, Neda, and Ghorbanzadeh, Jahangir (2011). Investigating the effective factors on the probability of the lack of credit loans payment (A case study of real customers in Export Development Bank of Iran), financial knowledge and paper analysis, 12, pp. 111-137.

[10] Kimiagari, Mohammadali, Amini, Mohammadjafar, TabatabaeiArani, Hamid, Hosseini, Leila (2012). Credit risk model of credit customers loans (A case study of Bank Melli,Shahre Reza branch). The ninth international conference of industrial engineering.

[11] Kordlooei, Hamidreza, Namdar, Siavash (2014). Credit risk management of customers' validation, published thesis, Islamic Azad University of Eslamshahr.

[12] Mirzaei, Ali (2013). Investigating the relationship between credit risk and cost price in Bank Keshavarzi (A case study in Kerman). Published thesis in Kerman.

[13] Mahmoodi, Nader, Sharifi, Hossein (2013). Investigating effective reasons and factors contributing to the lack of refundment of quick loans in Bank Melli, ShahreKord branch. The first international electronic conference in Iran economy.

[14] Mohsen, Nazari (2001). Management macroeconomic, Negahe-Danesh publication.

[15] Hemati, Abdolnaser, and Mohebinezhad, Shadi (2009). Evaluating the effect of macroeconomic variables on bank credit risk, EconomyBulletin,special for the banks, pp.39-53. 